\title{
A cost-effectiveness and safety analysis of dual antiplatelet therapy comparing aspirin- clopidogrel to aspirin-ticagrelor in patients with acute coronary syndrome
}

\author{
Nafrialdi, ${ }^{1}$ Novita M. Handini, ${ }^{2}$ Instiaty, ${ }_{1}^{1}$ Ika P. Wijaya ${ }^{3}$ \\ ${ }^{1}$ Department of Pharmacology and Therapeutic, Faculty of Medicine, Universitas Indonesia, Jakarta, Indonesia \\ ${ }^{2}$ Postgraduate student of Clinical Pharmacology, Faculty of Medicine, Universitas Indonesia, Jakarta, Indonesia \\ ${ }^{3}$ Department of Internal Medicine, Faculty of Medicine, Universitas Indonesia, Cipto Mangunkusumo Hospital, Jakarta, Indonesia
}

\section{ABSTRACT}

Background: Dual antiplatelet therapy (DAPT) using either an aspirin-clopidogrel (A-C) combination or aspirin-ticagrelor (AT) combination has become the standard therapy for acute coronary syndrome (ACS). Ticagrelor shows better pharmacokinetic profiles but is more expensive. This study aimed to compare cost-effectiveness and safety profiles of A-C versus A-T in patients with ACS.

Methods: This was a retrospective cohort study of ACS patient at the Cipto Mangunkusumo Hospital between 2014 and 2016. ACS patients treated for the first time with A-T or A-C were included. Occurrence of major adverse cardiovascular events (MACE) within 3, 6, 9, and 12 months were used as effectiveness outcomes, while safety outcomes were measured based on the incidence of adverse drug reactions (major and minor bleeding, dyspnea, and hyperuricemia). Cost-effectiveness analysis was presented as incremental cost-effectiveness ratio (ICER).

Results: Data records obtained from 123 ACS patients treated with A-C and 57 ACS patients treated with A-T were evaluated. Within the first three months, the MACE rate was $15.8 \%$ in the A-T group and 31.7\% in the A-C group (RR: 0.498 , 95\% CI: $0.259-$ $0.957, \mathrm{p}=0.039)$. There was no statistically significant difference observed in the number of MACE between groups after 6,9 , and 12 months. The A-T group had a higher incidence of major bleeding (melena) than the A-C group (5.3\% vs $1.62 \%, \mathrm{p}=0.681$ ), especially in geriatric patients. Minor bleeding was observed in three patients of the A-C group, but in none of the patients in the A-T group. The cost of ICER was IDR 279,438, indicating the additional cost needed for avoiding MACE within 3 months, if A-T was used.

Conclusion: The aspirin-ticagrelor combination is a clinically superior and cost-effective option for MACE prevention among ACS patients, especially during the first three months of DAPT, with a slight but not significantly higher major bleeding risk when compared to the aspirin-clopidogrel combination.

Keywords: acute coronary syndrome, clopidogrel, dual antiplatelet therapy, ticagrelor

pISSN: 0853-1773• eISSN: 2252-8083• https://doi.org/10.13181/mji.v27i4.3024 • Med J Indones. 2018;27:262-70

- Received 30 May 2018 • Accepted 28 Sep 2018

Corresponding author: Nafrialdi

nafrialdi@gmail.com

Copyright @ 2018 Authors. This is an open access article distributed under the terms of the Creative Commons Attribution-NonCommercial 4.0 International License (http://creativecommons.org/licenses/by-nc/4.0/), which permits unrestricted non-commercial use, distribution, and reproduction in any medium, provided the original author and source are properly cited. 
Coronary arterial disease (CAD) is the main cause of death in both developed and developing countries. ${ }^{1}$ According to the data published by World Health Organization (WHO) in 2012, ischemic heart disease (IHD) has resulted in mortality in 7.4 million individuals worldwide. The 2013 Basic Health Research performed in Indonesia revealed that CAD was the seventh most frequent non-communicable disease in Indonesia. ${ }^{2}$ According to the WHO prediction in 2013, mortality caused by CAD may reach $17.5 \%$ of total mortality cases in Indonesia. ${ }^{3}$

\section{Dual antiplatelet therapy (DAPT)} and anticoagulant therapy have become the mainstay treatments for acute coronary syndrome (ACS). The most widely used DAPT is combination of aspirin with one of the adenosine diphosphate (ADP)-receptor antagonists of the thienopyridine group. Clopidogrel was the most widely used (ADP)-receptor antagonist from the thienopyridine group. However, it is a prodrug that requires conversion to its active form by cytochrome $\mathrm{P} 450$ enzymes (mainly the CYP2C19 isoenzyme), which show polymorphism., ${ }^{4,5}$ This polymorphism is associated with heterogeneous responses. Some patients may be partially responsive or even irresponsive to clopidogrel, this may result in a high recurrence rate of IHD $(10 \%$ of IHD, and $2 \%$ of stent thrombosis). ${ }^{2}$

Ticagrelor is a newer generation of ADPreceptor antagonists and is a directly active drug. Thus, the sort of response variation encountered with clopidogrel is not expected with ticagrelor use. The 2009 Platelet Inhibition and Patient Outcomes (PLATO) study reported that ticagrelor is superior to clopidogrel in preventing the recurrence of ischemic events such as myocardial infarctions and ischemic strokes. ${ }^{6}$ However, adverse events such as gastrointestinal and intracranial bleeding were reported more frequently with ticagrelor use compared to clopidogrel use. In addition, ticagrelor use was associated with other side effects such as epistaxis, shortness of breath (dyspnea), and a higher withdrawal rate. ${ }^{7}$

Although there is a trend toward using ticagrelor, many centers in Indonesia still use clopidogrel because of its cheaper price and availability under the coverage of the National Health Insurance System. Considering the different efficacy and safety profiles of these drugs as reported in the PLATO study of Western people, we intend to evaluate the cost-effectiveness and safety profile of these two regimens of DAPT in patients with ACS at the Cipto Mangunkusumo Hospital, Jakarta.

\section{METHODS}

\section{Study Design}

This is a retrospective cohort study on ACS patients hospitalized at the Cipto Mangunkusumo Hospital during the period between January 2014 and December 2016. Clinical data were collected from patients' medical records and drug data. All treatment costs were collected from the financial department of the hospital. The study protocol was approved by the Ethics Committee of the Faculty of Medicine, Universitas Indonesia (No. 399/UN2.F1/ETIK/2017).

\section{Participants}

Eligible patients were adult (age $\geq 18$ years), hospitalized and diagnosed for the first time with ACS [ST-segment-elevation myocardial infarction (STEMI), non-ST-segment-elevation myocardial infarction (NSTEMI) or unstable angina pectoris (UAP)]. Patients who received either aspirin-clopidogrel (A-C) or aspirinticagrelor (A-T) combination as DAPT for a minimum period of 3 months were included. Patients who were switched from A-C to A-T or vice versa were included in the group of their initial treatment. Patients who received drugs other than clopidogrel and ticagrelor in their dual antiplatelet regimen, and patients with incomplete data records were excluded.

\section{Outcomes}

Assessment of effectiveness in both groups was based on the incidence of major adverse cardiovascular events (MACE) such as cardiovascular death, non-fatal myocardial infarction, stent thrombosis, and ischemic stroke during observation timepoints of 3,6 , and 12 months. The safety assessment consisted of bleeding (major and minor bleeding), and other side effects (dyspnea and hyperuricemia) during 3 months of observation. 


\section{Statistical considerations}

The sample size for evaluating MACE was calculated by using the formula for two proportions of two independent sample groups: ${ }^{8}$

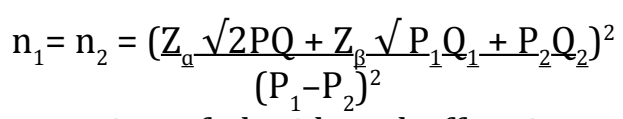

$\mathrm{P}_{1}=$ proportion of clopidogrel effect in avoiding major CV event $=80 \%=0.8$ (from reference 6 )

$\mathrm{P}_{2}=$ proportion of ticagrelor effect in avoiding major CV event $=90 \%=0.9$ (from reference 6 )

By taking $\mathrm{Z}_{\mathrm{a}}=1.96 ; \quad \mathrm{Z}_{\beta}=0.842 ; \quad$ and $\mathrm{P}=(0.8+0.9) / 2$, it was established that a minimum sample size of 116 was needed for each group. Effectiveness and safety parameters of the two regimens of dual antiplatelet $(\mathrm{A}-\mathrm{C}$ and $\mathrm{A}-\mathrm{T})$ were presented as descriptive statistics at 3,6 , and 12-month evaluations. Comparison between the incidences of MACE in both groups was performed using the Chi-square test, and a p-value of $<0.05$ was taken as the limit of statistical significance.

\section{Cost-effectiveness analysis (CEA)}

CEA was calculated based on the incremental cost-effectiveness ratio (ICER). It is defined by the difference in cost between the two regiments ( $\mathrm{A}-\mathrm{C}$ vs $\mathrm{A}-\mathrm{T})$, divided by the difference in their effects, which is the percentage of patients without MACE. The ICER can be calculated by the following formula: ICER=[C1-C0]/[E1-E0], where $\mathrm{C} 1$ and $\mathrm{E} 1$ are the cost and effect in one group (A-T) group and $\mathrm{C} 0$ and $\mathrm{E} 0$ are the cost and effect in the control (A-C) group. ${ }^{9}$

\section{RESULTS}

Data were retrieved from 1,059 medical records from patients (inpatients and outpatients) diagnosed with ACS at the Cipto Mangunkusumo Hospital from 2014 to 2016. Of those patients, 879 were excluded. Of the excluded patients, 484 were due to incomplete data, 267 did not continue treatment in this hospital, and 128 due to miscoding of their diagnosis. Finally, 123 patients who received aspirin-clopidogrel and 57 patients who received aspirin-ticagrelor were eligible for analysis.

Table1 shows demographic characteristics of patients belonging to A-C and A-T groups. A-C groups had more patients with comorbidities
Table 1. Demographic characteristics of study subjects

\begin{tabular}{|c|c|c|}
\hline Variable & $\begin{array}{c}\text { A-C group } \\
n=123\end{array}$ & $\begin{array}{c}\text { A-T group } \\
n=57\end{array}$ \\
\hline \multicolumn{3}{|l|}{ Age, n (\%) } \\
\hline$<75$ years & $120(97.6)$ & $54(94.7)$ \\
\hline$\geq 75$ years & $3(2.4)$ & $3(5.3)$ \\
\hline Mean age, years & 58.2 & 60.89 \\
\hline \multicolumn{3}{|l|}{ Gender, n (\%) } \\
\hline Male & $86(69.9)$ & 48 (84.3) \\
\hline Female & $37(30.1)$ & $9(15.8)$ \\
\hline \multicolumn{3}{|l|}{ BMI, n (\%) } \\
\hline Underweight & $3(2.4)$ & $0(0)$ \\
\hline Normal & $112(91.1)$ & 48 (84.2) \\
\hline Overweight & $4(3.3)$ & $3(5.3)$ \\
\hline Obese & $4(3.3)$ & $6(10.5)$ \\
\hline \multicolumn{3}{|l|}{ CAD diagnosis, $\mathrm{n}(\%)$} \\
\hline STEMI & $41(33.34)$ & $30(52.63)$ \\
\hline NSTEMI & $20(16.26)$ & $6(10.52)$ \\
\hline UAP & $62(50.4)$ & $21(36.84)$ \\
\hline \multicolumn{3}{|l|}{ Comorbidities, n (\%) } \\
\hline Diabetes mellitus & $38(30.9)$ & $30(52.6)$ \\
\hline Congestive heart failure & $68(55.3)$ & $12(21.1)$ \\
\hline Hypertension & $74(60.2)$ & 45 (78.9) \\
\hline Hyperlipidemia & $47(38.2)$ & $18(31.6)$ \\
\hline CKD & $10(8.1)$ & $6(10.5)$ \\
\hline CKD with dialysis & $2(1.6)$ & $0(0)$ \\
\hline Liver disease & $23(18.7)$ & $9(15.8)$ \\
\hline GI diseases & $27(22.0)$ & $3(5.3)$ \\
\hline Tuberculosis & $2(1.6)$ & $0(0)$ \\
\hline No comorbidities & $1(0.8)$ & $3(5.26)$ \\
\hline
\end{tabular}

A-C=aspirin-clopidogrel; A-T=aspirin-ticagrelor; BMI=body mass index; $\mathrm{CAD}=$ coronary artery diseases; STEMI=STelevated myocardial infarction; NSTEMI=non-ST-elevated myocardial infarction; UAP=unstable angina pectoris; $\mathrm{CKD}=$ chronic kidney disease

such as congestive heart failure (CHF), chronic kidney disease, hyperlipidemia, liver disease, gastrointestinal disorders, and tuberculosis. The A-T group had more metabolic comorbidities such as diabetes mellitus, hypertension, and hyperlipidemia. Both groups were dominated by male patients. The A-T group had more obese patients, while there were more underweight patients in the A-C group. Accounting for the type of acute coronary syndrome, STEMIs were predominantly found in the A-T group, while NSTEMIs and UAPs were predominantly found in the $\mathrm{A}-\mathrm{C}$ group. 
Table 2. Some clinical aspects and concomitant drugs use in both groups

\begin{tabular}{|c|c|c|}
\hline Variables & $\begin{array}{c}\text { A-C group } \\
n=123\end{array}$ & $\begin{array}{c}\text { A-T group } \\
n=57\end{array}$ \\
\hline $\begin{array}{l}\text { Duration of DAPT, } \\
\text { months [median (range)] }\end{array}$ & $11(3$ to 34$)$ & $6(3$ to 21$)$ \\
\hline $\begin{array}{l}\text { LOS, days [median } \\
\text { (range)] }\end{array}$ & 7 (1 to 60$)$ & 5 (1 to 56$)$ \\
\hline Switching, n (\%) & $6 / 123(4.90)$ & $3 / 57(5.3)$ \\
\hline \multicolumn{3}{|l|}{ DAPT score-n (\%) } \\
\hline Score $\geq 2$ & $87(70.7)$ & 45 (78.9) \\
\hline Score $\leq 1$ & $36(29.3)$ & $12(21.1)$ \\
\hline \multicolumn{3}{|l|}{$\begin{array}{l}\text { HAS-BLED score, } \\
\text { n (\%) }\end{array}$} \\
\hline Low risk & $51(41.5)$ & $36(63.2)$ \\
\hline Moderate risk & $42(34.1)$ & 12 (21.1) \\
\hline High risk & $30(24.4)$ & 9 (15.8) \\
\hline \multicolumn{3}{|l|}{$\begin{array}{l}\text { Other drugs with } \\
\text { potential interactions }\end{array}$} \\
\hline Omeprazole & $13(10.6)$ & $3(5.3)$ \\
\hline Oral anticoagulant & $16(13.0)$ & $0(0)$ \\
\hline Lansoprazole & $92(74.8)$ & $24(42.1)$ \\
\hline Sucralfate & $22(17.9)$ & $9(15.8)$ \\
\hline NSAIDs & $11(8.9)$ & $0(0)$ \\
\hline \multicolumn{3}{|l|}{$\begin{array}{l}\text { Invasive procedures, } \\
\text { n (\%) }\end{array}$} \\
\hline PCI & $79(64.2)$ & $48(84.2)$ \\
\hline Stenting & $77(62.6)$ & 45 (78.9) \\
\hline CABG & $14(11.4)$ & $3(5.3)$ \\
\hline
\end{tabular}

A-C=aspirin-clopidogrel; $\quad$ A-T=aspirin-ticagrelor; $\quad$ DAPT=dual antiplatelettherapy; LOS=length of stay; HAS-BLED=hypertension, abnormal renal or liver function, stroke, bleeding; NSAIDs=nonsteroidal anti-inflammatory drugs; $\mathrm{PCI}=$ percutaneous coronary intervention; $\mathrm{CABG}=$ coronary artery bypass grafting

\section{Clinical aspects and concomitant drug usage}

The average duration of $\mathrm{A}-\mathrm{C}$ combination treatment was 11 months (range: 3 to 34 months), and the average duration of A-T combination treatment was 6 months (range: 3 to 21 months). There were more patients who switched from A-C to A-T treatment, compared to the inverse switch in treatment. DAPT and HAS-BLED scores were comparable between the two groups. Concomitant use of strong cytochrome inhibitors (omeprazole) and strong CYP3A4 inducers (rifampicin) were higher in A-C group (Table 2).

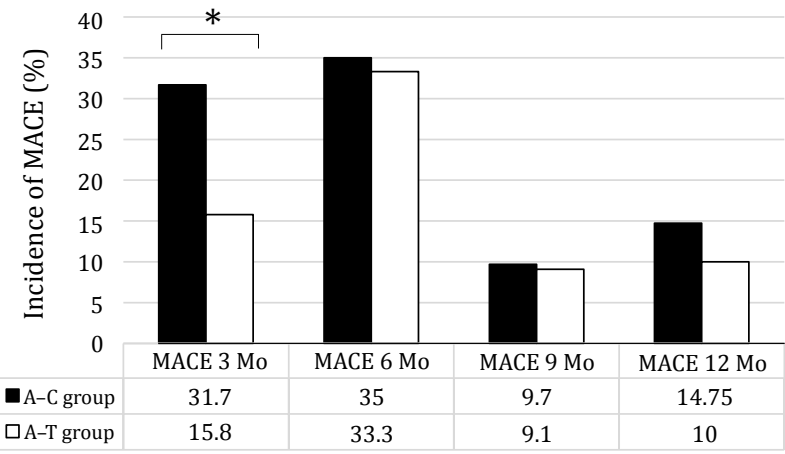

Figure 1. Major cardiovascular events (MACE) during observation periods of $3,6,9$, and 12 months in acute coronary syndrome patients treated with combination of either aspirin-clopidogrel (A-C group) or aspirin-ticagrelor (A-T group). ${ }^{*} \mathrm{p}<0.05 \mathrm{~A}-\mathrm{C}$ vs $\mathrm{A}-\mathrm{T}$ group

\section{Efficacy assessment: major adverse cardiovascular events in patients receiving A-C and A-T}

Figure 1 shows that during the 3-month period of observation, the incident of MACE was significantly higher among patients in the group receiving $\mathrm{A}-\mathrm{C}$ compared to those in the $\mathrm{A}-\mathrm{T}$ group $(31.7 \%$ vs $15.8 \%, p=0.039$, RR $0.498, \mathrm{CI}$ $95 \%=0.259-0.957)$. The most frequent MACE was acute myocardial infarction ( 36 out of 123 ), while stroke, stent thrombosis, and cardiovascular death were experienced by one patient each in $\mathrm{A}-\mathrm{C}$ group, compared to none in the $\mathrm{A}-\mathrm{T}$ group. The 6- and 9-month periods of observation gave an almost identical percentage of patients with MACE. At 12 months, there was a trend, though not significant, indicating a lower incidence of myocardial infarction in A-T group of patients compared to those in the A-C group $(10.0 \%$ vs $14.75 \%)$.

\section{Safety outcome within 3 months}

Major bleeding was higher in the A-T group $\{3 / 57(5.3 \%)\}$ compared to $\mathrm{A}-\mathrm{C}$ group $\{2 / 123$ (1.62\%, $\mathrm{p}=0.681 ; \mathrm{RR}=1.618 ; \mathrm{CI}$ $95 \%=0.374-6.994)\}$. On the contrary, minor bleeding was higher in the A-C group $(2.4 \%$ vs $0 \%)$. We did not find any cases of dyspnea or hyperuricemia in either group (Table 3).

\section{Confounding factors}

As shown in table 4, the occurrence of MACE within the 3-month observation period was significantly higher in the $\mathrm{A}-\mathrm{C}$ group than in the A-T group. Further analysis of confounding factors revealed that hypertension 
Table 3. Safety outcomes for patients on aspirin-clopidogrel or aspirin-ticagrelor during a three-month observation period

\begin{tabular}{lcccc}
\hline End points & A-C group, n (123) & A-T group, n (57) & Hazard ratio for A-T (95\% CI) & p-value \\
\hline Major bleeding, n (\%) & $2(1.62)$ & $3(5.3)$ & $1.618(0.374-6.994)$ & 0.681 \\
Minor bleeding, n (\%) & $4(3.25)$ & $0(0)$ & - & 0.309 \\
Dyspnea, n (\%) & $0(0)$ & $0(0)$ & - & - \\
Hyperuricemia, n (\%) & $0(0)$ & $0(0)$ & - & - \\
\hline
\end{tabular}

A-C=aspirin-clopidogrel; A-T=aspirin-ticagrelor

Table 4. Analysis of confounding factors in patients with MACE within 3 months of observation

\begin{tabular}{|c|c|c|c|c|}
\hline Variables & $\mathrm{A}-\mathrm{C}, \mathrm{n}(\%)$ & A-T, n (\%) & RR $(95 \%$ CI $)$ & p-value \\
\hline MACE in 3 months & $39 / 123$ (29.3) & 9/57 (15.8) & $0.498(\mathrm{CI}=0.259-0.957)$ & 0.039 \\
\hline \multicolumn{5}{|l|}{ Age } \\
\hline$<75$ years & $37 / 39$ (94.8) & $9 / 9(100)$ & $1.053(\mathrm{CI}=0.980-1.130)$ & 1.00 \\
\hline$\geq 75$ years & $2 / 39(5.12)$ & $0 / 9(0)$ & - & - \\
\hline \multicolumn{5}{|l|}{ Body mass index } \\
\hline Underweight & $2 / 39(5.12)$ & $0 / 9(0)$ & - & - \\
\hline Obese & $1 / 39(2.5)$ & $0 / 9(0)$ & - & - \\
\hline \multicolumn{5}{|l|}{ Comorbidities } \\
\hline Diabetes mellitus & $16 / 39(41.0)$ & $1 / 9(11.1)$ & $0.317(\mathrm{CI}=0.048-2.113)$ & 0.242 \\
\hline CHF & $20 / 39(51.3)$ & $3 / 9(33.34)$ & $0.650(\mathrm{CI}=0.246-1.720)$ & 0.466 \\
\hline Hypertension & $22 / 39(56.4)$ & $9 / 9(100)$ & $1.739(\mathrm{CI}=1.332-2.270)$ & 0.019 \\
\hline Hyperlipidemia & $12 / 39$ (30.7) & $1 / 9(11.1)$ & $0.370(\mathrm{CI}=0.055-2.495)$ & 0.412 \\
\hline \multicolumn{5}{|l|}{ Drug interactions } \\
\hline Omeprazole & $3 / 39(7.7)$ & $0 / 9(0)$ & - & - \\
\hline Lansoprazole & $25 / 39$ (64.1) & $6 / 9(66.7)$ & $1.040(\mathrm{CI}=0.619-1.746)$ & 1.00 \\
\hline Sucralfate & 9/39 (23.1) & $3 / 9(33.3)$ & $1.444(\mathrm{CI}=0.487-4.282)$ & 0.671 \\
\hline
\end{tabular}

$\mathrm{A}-\mathrm{C}=$ aspirin-clopidogrel; $\mathrm{A}-\mathrm{T}=$ =aspirin-ticagrelor; $\mathrm{MACE}=$ major adverse cardiovascular events; $\mathrm{CHF}=$ congestive heart failure

had a significant influence on the occurrence of MACE ( $p=0.019$; $R R=1.739$; CI 95\%=1.3322.270), while other comorbidities (DM, CHF, and dyslipidemia) and demographic data (age, BMI, gender) did not significantly influence MACE (Table 4). With regards to drug-drug interactions, omeprazole and rifampicin influence on cytochrome P450 activity, and hence would influence the metabolism of clopidogrel. However, the analysis did not show that the influence of these drugs on MACE were statistically significant.

\section{Cost analysis}

Table 5 shows the average of total treatment costs between the 2014 and 2016 in both $\mathrm{A}-\mathrm{C}$ and $\mathrm{A}-\mathrm{T}$ groups. The cost for each patient was calculated for 3 months following admission for acute coronary syndrome.
Application of the formula for calculating the incremental cost-effective ratio revealed the following results: ICER=(IDR 79,296,071-IDR74, $849,993) /(84.2 \%-68.3 \%)=$ IDR 279,438 . It means that an additional cost of IDR 279,438 was needed to avoid one MACE when using aspirinticagrelor combination compared to aspirinclopidogrel combination.

\section{DISCUSSION}

This was a retrospective cohort study on patients with ACS who received dual antiplatelet, clopidogrel or ticagrelor in combination with aspirin for at least 3 months. A total of 123 eligible patients were in the aspirin-clopidogrel group, and a total of 57 patients were in the aspirinticagrelor group. The subjects in both groups 
Table 5. Total cost covered by the National Health Insurance for patients with acute coronary syndrome who received aspirinclopidogrel (A-C group) and aspirin-ticagrelor (A-T group) at the Cipto Mangunkusumo Hospital between 2014 and 2016

\begin{tabular}{lcccc}
\hline & \multicolumn{2}{c}{ A-C group (n=123) } & \multicolumn{2}{c}{ A-T group (n=57) } \\
\hline Cost components & Mean (IDR) & SD & Mean (IDR) & SD \\
\hline Drug cost & $18,115,140$ & $11,560,127$ & $14,837,325$ & $5,273,342$ \\
Intervention cost & $39,098,597$ & $29,186,775$ & $34,087,436$ & $15,686,881$ \\
Room cost & $3,457,408$ & $2,846,765$ & $2,811,818$ & $1,564,126$ \\
Nursing cost & $8,769,181$ & $7,977,513$ & $11,466,454$ & $2,533,195$ \\
Outpatient cost & $1,012,530$ & 485,974 & $1,127,400$ & 160,164 \\
Readmission cost & $19,722,716$ & $12,515,736$ & $18,261,260$ & $29,270,650$ \\
Total cost & $77,200,512$ & $49,067,716$ & $80,931,579$ & $37,899,601$ \\
Total cost after discounting 3\% & $74,849,993$ & $47,983,339$ & $79,293,071$ & $37,282,676$ \\
\hline
\end{tabular}

were predominantly male $(69.9 \%$ and $84.3 \%$, respectively). Accounting for ACS diagnosis, more patients in A-T group presented with STEMI (52.63\% vs $33.34 \%$, respectively), while more UAP (50.4\% vs $36.84 \%)$, and NSTEMI (16.26\% vs $10.52 \%)$ cases presented in the A-C group.

The duration of A-C use among the subjects ranged between 3 and 34 months, with a median value of 12 months. The duration of A-T use ranged between 3 and 21 months, with a median value of 6 months. The previous standard DAPT treatment for ACS was aspirin and clopidogrel. The use of ticagrelor at the Cipto Mangunkusumo Hospital started in 2014. Of the total of 57 subjects on ticagrelor in this study, $16 \%$ received it in $2014,21 \%$ in 2015 , and $63 \%$ in 2016 . Of the 123 patients on clopidogrel, $26 \%$ received it in 2014, 43\% in 2015, and 31\% in 2016. Another study by Kim et $\mathrm{al}^{10}$ in the United States also reported a trend of increased ticagrelor use since 2013, accompanied by trend of decreased clopidogrel and prasugrel use.

\section{Efficacy outcomes}

The main parameter we used to evaluate efficacy outcomes was the incidence of major cardiovascular events (MACE) including myocardial infarctions, cardiovascular deaths, strokes, and stent thromboses. In our study, the evaluation of MACE was done in 3 months intervals. This was because thrombin and platelets have their highest activity in the first three-month period. Therefore, the probability of MACE was its highest in this period. In addition, some of the patients recruited for this study received DAPT for only 3 months.
The incidence of MACE was significantly lower in patients who received ticagrelor (15.8\%) compared to those who received clopidogrel (31.7\%) within the first 3 months. Although cumulative one-year MACE was not significantly different in both group, the most common MACE in the first 3 months was acute myocardial infarction, followed by stroke, stent thrombosis, and the least common was cardiovascular death. The total number of MACE over 6 months was almost identical between the two groups $(33.3 \%$ vs $35 \%, \mathrm{p}=0.385)$. The same pattern was also observed over 9 months $(9.1 \%$ and $9.7 \%$ in A-T and $\mathrm{A}-\mathrm{C}$ group, respectively). Over 12 months, we observed a lower incidence of MACE in patients who received A-T compared to those who received A-C (10\% vs $14.75 \%)$. However, this difference did not reach statistical significance.

The PLATO study also reported a lower incidence of MACE in patients on ticagrelor compared to those on clopidogrel $(9.8 \%$ vs $11.7 \%, \mathrm{p}<0.001$ ) after 12 months of DAPT use. ${ }^{5,11}$ Although the difference in MACE between the two DAPTs in the PLATO study was relatively small, the large sample size yielded high statistical significance. The superior efficacy of ticagrelor in preventing MACE may be attributed to its direct inhibitory effect on P2Y12 receptor and platelet activation. Ticagrelor acts to directly inhibit the P2Y12 receptor on the platelet surface and create antiplatelet effect. However, clopidogrel is a prodrug that requires activation by the cytochrome $\mathrm{P} 450$ before it can exert an antiplatelet effect. ${ }^{4,12}$ Clopidogrel is activated in the liver by the CYP2C19 isoenzyme of CYP450. Inhibition of platelet aggregation by clopidogrel is known to 
vary considerably among patients. This variability may result from several factors including genetic variation, clinical comorbidities, or drug-drug interactions. The effects of polymorphism in the CYP219 gene on variable response to clopidogrel, including poor response and resistance in mutant subjects have been previously described.

In our study, 36 of 123 patients (29.3\%) under aspirin-clopidogrel treatment experienced MACE within 3 months compared to 9 of $57(15.8 \%)$ patients under aspirinticagrelor treatment. We were unable to conclude whether the higher incidence of acute myocardial infarctions in the clopidogrel group is attributable to clopidogrel resistance, since we did not perform genetic studies. In addition, we do not have data on the prevalence of clopidogrel resistance in the native Indonesian population. Guha et $\mathrm{al}^{13}$ in Kolkata India, conducted a study in 144 patients with ACS and reported clopidogrel resistance in $12.5 \%$ of patients and poor response in $19.44 \% .{ }^{11}$ Another study conducted by Kumar et al ${ }^{14}$ involving 39 ACS patients in India showed a $2.54 \%$ of clopidogrel resistance in $2.54 \%$ of patients and partial response in $12.70 \%$.

\section{Confounding analysis}

Clinical comorbidities that potentially contribute to the occurrence of MACE are diabetes mellitus, history of coronary disease, high BMI, heart failure, chronic kidney disease, and smoking. In our study subjects, comorbidities were not uniformly distributed between the two groups. DM and obesity were both higher in the A-T group, while heart failure was more frequent in the A-C group. The Studies of Left Ventricular Dysfunction (SOLVD) reported that patients with acute myocardial infarction were twice more likely to be hospitalized if they had heart failure. ${ }^{15}$ On the other hand, the risk of mortality in heart failure patients was four times higher, if they had a myocardial infarction.

When drug-drug interactions were examined, only omeprazole potentially interfered with clopidogrel action through inhibition of CYP. There was a slightly higher number of patients in the A-C group that received omeprazole compared to those in A-T group (10.6 vs 5.3\%). In addition, more patients in the A-C group also received NSAIDs. NSAIDs may play a role in the higher incidence of acute myocardial infarctions, as they are known to increase the risk of recurrence of coronary disease. However, the small sample size did not allow us to confirm this conclusion. Further studies with adequate sample sizes are needed to confirm this issue. Another possible influencing factor is the background to the ACS diagnosis. As seen in table 1, a higher number of patients in the ticagrelor group underwent primary percutaneous coronary intervention (PCI) and stent compared to the clopidogrel group. It is likely that this intervention plays a role in the lower incidence of acute myocardial infarctions within 3 months of DAPT treatment.

\section{Safety assessment}

Major bleeding within three months occurred in 3 of 57 (5.3\%) patients of A-T group. They had melena within 1 to 2 weeks after ticagrelor consumption. Three patients were aged more than 75 years old, with normal BMI and comorbidities of DM, hypertension, and CHF. They were diagnosed with STEMI and had no concomitant drug with potential to increase bleeding risk. These patients were then switched to clopidogrel for 12 months, with no recurrence of bleeding reported. The PLATO study noted that the risk of bleeding increases in geriatric patients. ${ }^{11}$ Each decade of age increases the risk for major bleeding with hazard ratio by 1.61 ; CI 95\%, $0.374-$ 6.994). However, subanalysis in PLATO study did not prove an increase in risk of major bleeding in patients older than 75 years old. ${ }^{11}$

Of the 123 patients $(1.62 \%)$ in $\mathrm{A}-\mathrm{C}$ group, two experienced bleeding. One of them had melena, while the other had anemia that required transfusion. The patient with melena was 72 years old, and experienced melena after 5 months of treatment with aspirin+clopidogrel. Aspirin was then discontinued, while clopidogrel was continued. The patient with anemia was 52 years old with a history of warfarin use, which potentially interacts with clopidogrel. Anemia reported after 7 months of treatment with aspirin, clopidogrel, and warfarin. Clopidogrel and warfarin were withdrawn for 1 month; clopidogrel use has been resumed since. No MACE has been subsequently reported in this patient.

Minor bleeding was noted in 4 of 123 (3.25\%) patients in the A-C group, and in none of the patients in the A-T group. Presentation of bleeding was respectively, epistaxis, gingival bleeding, and 
hematuria. All these patients experienced minor bleeding while receiving DAPT concomitantly with an anticoagulant such as warfarin and enoxaparin. It was concluded that bleeding in these patients was attributable to warfarin or enoxaparin use, rather than the DAPT itself.

We did not find other side effects such as dyspnea and hyperuricemia. This is likely a result of the limited sample size of patients. The PLATO study reported that the incidence of dyspnea and hyperuricemia was higher in patients who received ticagrelor. It is hypothesized that the sensation of dyspnea was associated with an inhibition of the P2Y12 receptor on sensory neurons, particularly when reversible inhibitors such as ticagrelor are used..$^{16,17}$

\section{Outcome cost}

Total cost comprises of all direct medical costs (drug cost, intervention cost, room cost, nursing cost, outpatient cost, and readmission cost). Total cost after 3\% discounting was higher in A-T group by IDR 79,293,071 than in the A-C (IDR 74,849,993). Referring to effectiveness of $\mathrm{A}-\mathrm{T}$ and $\mathrm{A}-\mathrm{C}$ treatment of $84.2 \%$ and $68.3 \%$, respectively, calculation of ICER gave the result of IDR 279,439. It means that for each MACE avoidance in a 3-month period, an addition of IDR 279,439 is spent when ticagrelor was used, instead of clopidogrel. This ICER was far below gross domestic product (GDP), which is IDR 49,000,800. According to the WHO recommendation, an ICER of $<1$ GDP is considered cost-effective, while an ICER $>3$ GDP is considered not cost-effective. ${ }^{8}$

\section{Limitation of the study}

According to sample size calculations, 116 subjects in each arm were required. However, in the aspirin-ticagrelor group, this number was not achieved because a large number of potential study recruits did not meet the inclusion criteria. Sample size shortages caused some limitations to this study, such as lack of statistical significance in the outcomes of the 6, 9, and 12-month observation periods. In studies with larger sample sizes, the differences were consistently reported up till a year of observation. Another limitation of this study is the difficulty in drawing conclusions about the role of confounding factors including comorbidities, concomitant treatments and types of ACS. However, the significant results in MACE outcomes and major bleeding from the 3-month observation period may describe the general profiles of efficacy and safety for these two treatment regimens.

Finally, we concluded from this study that ticagrelor is more effective in preventing MACE compared to clopidogrel. Statistically significant differences in outcomes were detected within 3 months of DAPT use. The higher incidence of major bleeding in ticagrelor group seemed to be inherent to its effectiveness. The higher frequency of minor bleeding among patients who received clopidogrel was likely due to concomitant use of anticoagulants. Cost-effectiveness analysis revealed that ticagrelor was more cost-effective than clopidogrel.

\section{Conflict of Interest}

Nafrialdi is one of the editorial board members, but was not involved in the review or decision process for this article.

\section{REFERENCES}

1. Finegold JA, Asaria P, Francis DP. Mortality from ischaemic heart disease by country, region, and age: statistics from World Health Organization and United Nations. Int J Cardiol. 2013;1658(2):934-45.

2. Kementerian Kesehatan RI. Riset Kesehatan Dasar: Riskesdas 2013 [Internet]. Available from:http://www. depkes.go.id/resources/download/general/Hasil\%20 Riskesdas\%202013.pdf

3. World Health Organization. Cardiovascular diseases (CVDs), [websites], Available from: http://www.who. int/mediacentre/factsheets/fs317/en/

4. Roffi M, Patrono C, Collet JP, Mueller C, Valgimigli M, Andreotti F, et al. 2015 ESC guidelines for the management of acute coronary syndromes in patients presenting without persistent ST-segment elevation: task force for the management of acute coronary syndromes in patients presenting without persistent STsegment elevation of the European society of cardiology (ESC). Eur Heart J. 2016;37(3):267-315.

5. Parodi G, Marcucci R, Valenti R, Gori AM, Migliorini A, Giusti $B$, et al. High residual platelet reactivity after clopidogrel loading and long-term cardiovascular events among patients with acute coronary syndromes undergoing PCI. JAMA. 2011;306(11):1215-23.

6. Wallentin L, Becker RC, Budaj A, Cannon CP, Emanuelsson $\mathrm{H}$, Held $\mathrm{C}$, et al. Ticagrelor versus clopidogrel in patients with acute coronary syndromes. N Engl J Med. 2009;361(11):1045-57.

7. Anonym. Brilinta. Ticagrelor. Azta zeneca, package insert.

8. Madiyono B, Sastroasmoro S, Budiman I, Purwanto SH. Perkiraan besar sampel. Dalam: Sastroasmoro $\mathrm{S}$, Ismail $\mathrm{S}$, editors. Dasar-dasar metodologi 
penelitiank linis. Jakarta: SagungSeto; 2014. p35287. [Indonesian].

9. Kementrian Kesehatan Republik Indonesia 2015. Pedoman penerapan kajian farmako ekonomi. P:18-41. [Indonesian].

10. Kim K, Lee TA, Touchette DR, DiDomenico RJ, Ardati AK, Walton SM. Contemporary trends in oral antiplatelet agent use in patients treated with percutaneous coronary intervention for acute coronary syndrome. J Manag Care Spec Pharm. 2017;23(1):57-63.

11. Husted S, James S, Becker RC, Horrow J, Katus H, Storey RF, et al. Ticagrelor versus clopidogrel in elderly patients with acute coronary syndromes: a substudy from the prospective randomized PLATelet inhibition and patient outcomes (PLATO) trial. Circ Cardiovasc Qual Outcomes. 2012;5(5):680-8.

12. Siller-Matula JM, Trenk D, Schrör K, Gawaz M, Kristensen SD, Storey RF, et al. Response variability to P2Y12 receptor inhibitors: expectations and reality.
JACC Cardiovasc Interv. 2013; 6(11):1111-28.

13. Guha S, Sardar P, Guha P, Roy S, Mookerjee S, Chakrabarti $\mathrm{P}$, et al. Dual antiplatelet drug resistance in patients with acute coronary syndrome. Indian Heart J. 2009;61(1):68-73.

14. Kumar S, Saran RK, Puri A, Gupta N, Sethi R, Surin WR, et al. Profile and prevalence of clopidogrel resistance in patients of acute coronary syndrome. Indian Heart J. 2007;59(2):152-6.

15. The SOLVD Investigators. Effect of enalapril on survival in patients with reduced left ventricular ejection fractions and congestive heart failure. $\mathrm{N}$ Engl J Med 1991;325(25):293-302.

16. Cattaneo M, Faioni E. Why does ticagrelor induce dyspnea? Thromb Haemost. 2012;108(6):1031-6.

17. Lucenteforte E, Lombardi N, Barchielli A, Torrini M, Mugelli A, Vannacci A. Ticagrelor-related dyspnea in patients with acute coronary syndrome: a three year cohort study. 2015. 